\title{
Cutaneous Mastocytosis with Persistent Blistering: Successful Treatment with Methylprednisolone and 3-Year Follow-Up Management
}

\author{
Rumyana Yankova $\cdot$ Tsvetana Abadjieva $\cdot$ Veselin Belovezhdov
}

To view enhanced content go to www.dermtherapy-open.com Received: February 22, 2015 / Published online: April 15, 2015

(C) The Author(s) 2015. This article is published with open access at Springerlink.com

\section{ABSTRACT}

Background: Mastocytosis is a rare disorder with diverse clinical manifestations. In cutaneous mastocytosis the mast cell infiltration is limited to the skin, but is often associated with systemic symptoms due to the release of mast cell mediators.

Case Report: We report a 6-month-old male infant who had skin lesions of various morphologies (macules, papules, plaques, and nodules) and sizes, persistent blistering and frequent flushing episodes for half a year. Vital signs and physical examinations were unremarkable. No abnormalities in the laboratory tests were found except for a serum tryptase level (STL) of $11.8 \mathrm{ng} / \mathrm{ml}$. The

Electronic supplementary material The online version of this article (doi:10.1007/s13555-015-0073-6) contains supplementary material, which is available to authorized users.

R. Yankova $(\bowtie) \cdot$ T. Abadjieva

Department of Dermatology and Venereology,

Medical University of Plovdiv, Plovdiv, Bulgaria

e-mail: rumyana.yankova@abv.bg

V. Belovezhdov

Department of General and Clinical Pathology,

Medical University of Plovdiv, Plovdiv, Bulgaria histological and immunohistochemical examinations confirmed the diagnosis of cutaneous mastocytosis. The patient was first treated with methylprednisolone, oral levocetirizine, and topical fusidic acid/betamethasone cream. Subsequently the treatment was tapered and stopped within 9 weeks. The child's symptoms improved and were successfully controlled with intermittent courses of ketotifen and topical hydrocortisone over 3 years.

Conclusion: Childhood

cutaneous mastocytosis usually has a favorable prognosis, but in some cases the disease can progress with skin manifestations necessitating a more active systemic and topical treatment.

Keywords: Blistering; Bullous mastocytosis; Corticosteroids; Cutaneous mastocytosis; Flushing; Methylprednisolone; Serum tryptase

\section{INTRODUCTION}

Mastocytosis comprises a heterogeneous spectrum of diseases characterized by a range of local and systemic symptoms. The current World Health Organization

(WHO) 
classification, updated in 2008, differentiates one exclusively cutaneous form from the systemic forms of mastocytosis [1-3]. Cutaneous mastocytosis (CM) is a condition classified according to clinical symptoms and identified by an abnormal accumulation of mast cells limited to the skin. Clinically, CM is divided into three main variants: maculopapular CM (or urticaria pigmentosa), characterized by disseminated small patches, papules, and plaques; diffuse CM, affecting large areas of the skin with yellow-red erythroderma-like, diffuse doughy-firm swellings and solitary mastocytoma, partly characterized by blistering and found predominantly in children. The much rarer forms are defined as the plaque form, the nodular form, and telangiectasia macularis eruptiva perstans. These disorders do not represent independent variants in the WHO classification and are assigned to maculopapular CM [1-4].

$\mathrm{CM}$ has been diagnosed in patients with disseminated bullous lesions, plaques, nodules, and other clinical presentations such as localized mastocytosis, solitary and multiple mastocytomas, and some other unusual morphologies [4, 5].

We present a 3-year-long follow-up of a child with skin lesions of various morphologies and sizes, continuous blistering, and frequent flushing during the first 6 months of his life. Successful treatment was achieved with a short methylprednisolone course and subsequent intermittent $\mathrm{H} 1$ receptor antagonist and topical treatments.

\section{CASE REPORT}

A 6-month-old male infant was referred with different types of skin lesions, persistent blistering, and frequent spontaneous flushing since birth. The child did not have any physical or psychomotor disturbances. No significant family or antenatal history data existed. Intermittent courses with oral $\mathrm{H} 1$ blockers and topical antibiotics and corticosteroids had been administered without improvement.

On admission, vital signs and chest and abdomen examinations were unremarkable, while hepatosplenomegaly and lymphadenopathy were absent. A variety of skin lesions (reddish-brown, partially with peau d'orange appearance, macules, papules, plaques, and nodules), sized 4-65 $\mathrm{mm}$, were distributed on the neck, trunk, buttocks, and extremities. Tense bullae, erosions, and crusts were revealed to overlay plaque surfaces (Figs. 1, 2a). Darier's sign was demonstrated (Fig. 2b). Oral mucosa was not affected. Within the first 2 days, we observed several flushing episodes, unprovoked by any triggering factors.

Laboratory findings did not disclose hematologic, biochemical, or liver function abnormalities. Serum tryptase level (STL) was $11.8 \mathrm{ng} / \mathrm{ml}$ (reference range $<11.4 \mathrm{ng} / \mathrm{ml}$ ). A biopsy taken from an elevated plaque with vesiculation revealed melanin in the basal/suprabasal layer, subepidermal bulla,

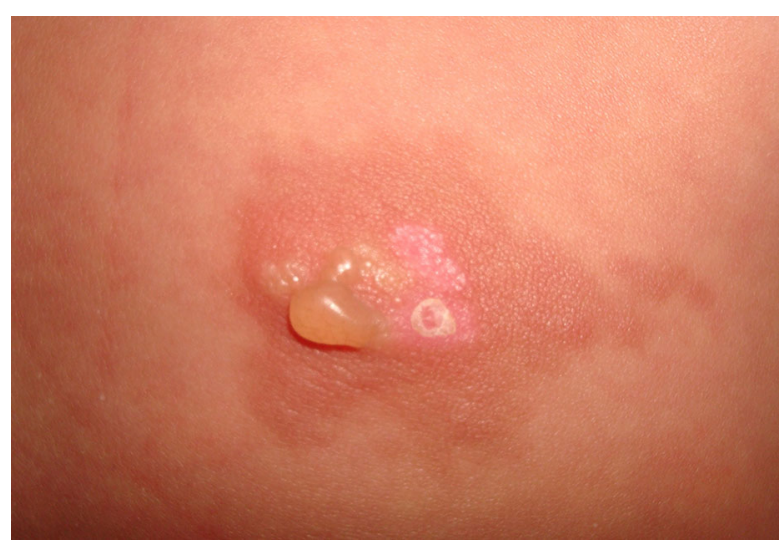

Fig. 1 One of the multiple reddish-brown plaques with peau d'orange appearance 

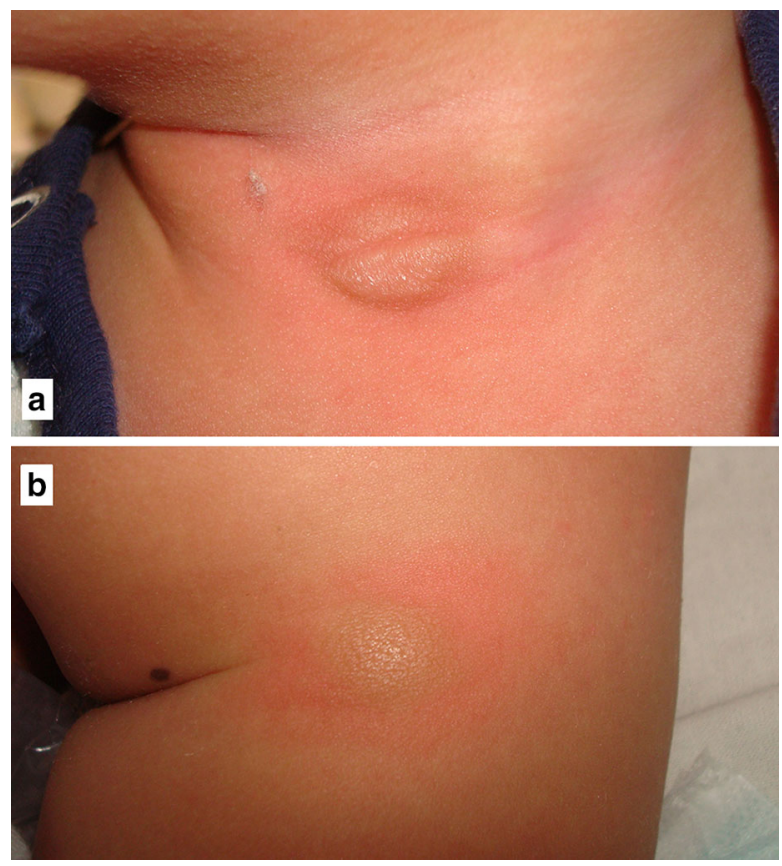

Fig. 2 a Nodular lesion on the neck, b Darier's sign

dense mast cell infiltration, and some eosinophils in the dermis (Fig. 3a). Immunohistochemical staining for CD117 antibody was positive (Fig. 3b). Toluidine blue and Giemsa stainings showed metachromatic granules in the cytoplasm of the infiltrating cells (Fig. 4a, b). The pediatric consultation did not reveal systemic symptoms.

The patient was initially treated with methylprednisolone $0.6 \mathrm{mg} / \mathrm{kg}$ once daily (o.d.) intramuscularly (3 days), oral levocetirizine $1.25 \mathrm{mg}$ o.d, $2 \%$ topical fusidic acid, and $0.1 \%$ betamethasone valerate cream. Subsequently, the dose of methylprednisolone was tapered, given orally $(0.5 \mathrm{mg} / \mathrm{kg}$ o.d [4 days], $0.5 \mathrm{mg} / \mathrm{kg}$ every other day [2 weeks], $0.5 \mathrm{mg} / \mathrm{kg}$ twice a week [2 weeks]) and stopped. After 10 days, levocetirizine was replaced with ketotifen $0.05 \mathrm{mg} / \mathrm{kg}$ twice daily for eight more weeks and the cream was replaced with $1 \%$ hydrocortisone cream for a month. The child was closely followed up during the treatment. His symptoms improved remarkably. There were no adverse effects of the
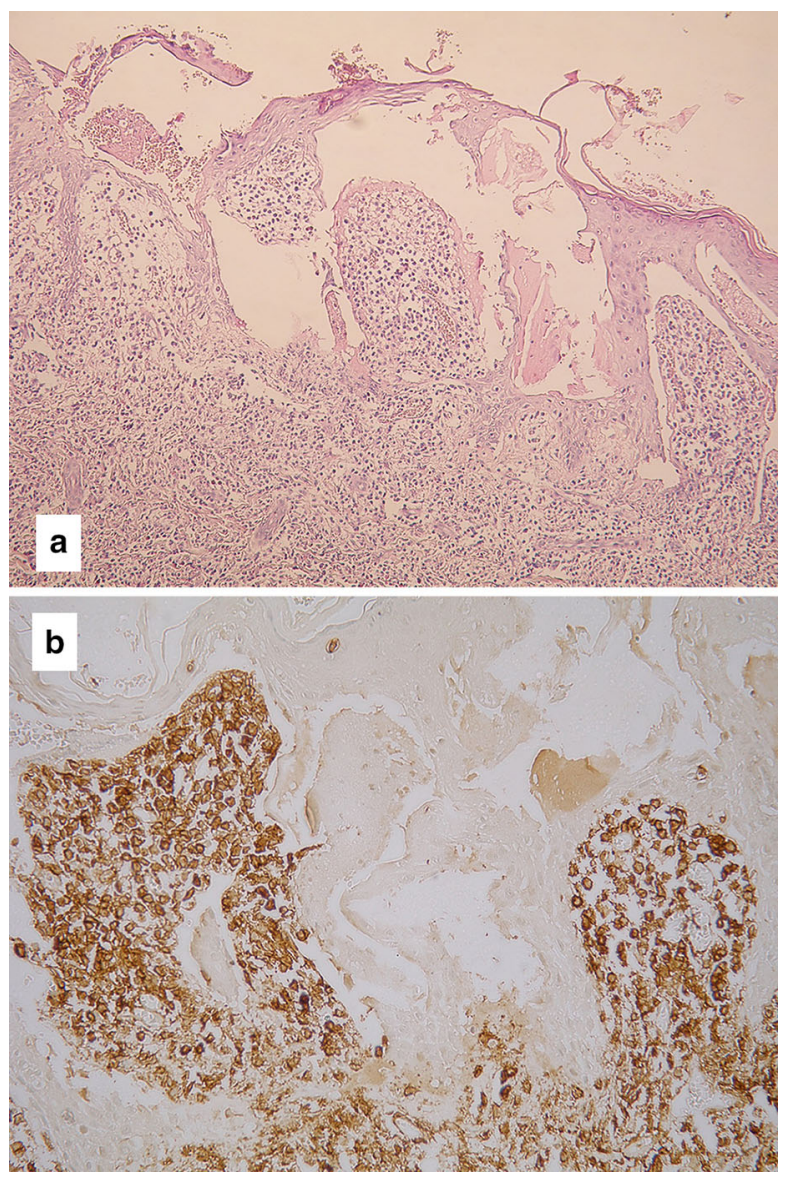

Fig. 3 a Subepidermal bulla and dermal infiltration $(\mathrm{H} \& \mathrm{E} ; \times 200)$, b CD117-positive mast cell infiltration $(\times 400)$

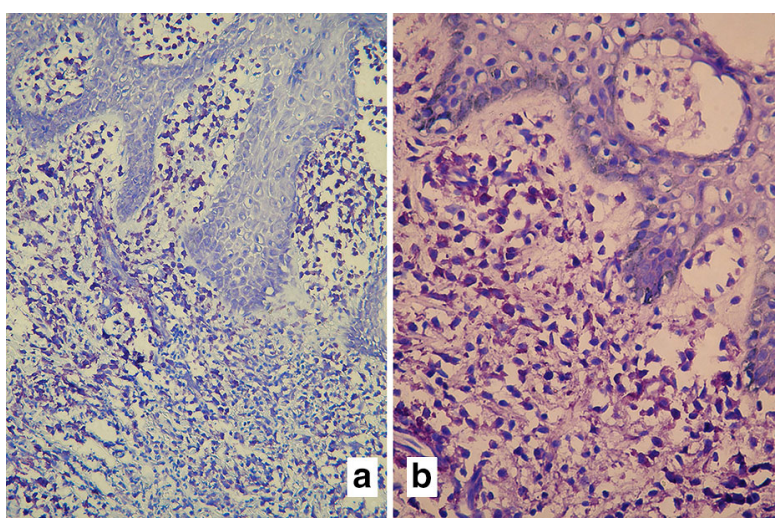

Fig. 4 a Toluidine blue $(\times 200)$ and b Giemsa $(\times 400)$ staining of mast cell dermal infiltration

therapy. Over the following 3 years, the clinical manifestations were successfully managed with intermittent ketotifen and topical hydrocortisone 
treatments. Parents were counseled on the avoidance of triggering factors for mediator release. At the last follow-up (3.5 years of age), only a few pale-brownish macules were seen with no blistering or isolated flushing episodes. The STL declined to $7.2 \mathrm{ng} / \mathrm{ml}$. For 3 years the patient did not show any symptoms consistent with systemic mastocytosis.

All procedures followed were in accordance with the ethical standards of the responsible committee on human experimentation (institutional and national) and with the Helsinki Declaration of 1964, as revised in 2013. Informed consent was obtained from the parent for the child being included in the study and for the publication of the patient photographs.

\section{DISCUSSION}

The diversity of $\mathrm{CM}$ skin manifestations is evident when reviewing the literature. With regard to cutaneous lesions, our case seems to belong to the maculopapular and nodular $\mathrm{CM}$, showing a range of lesions of various sizes and morphologies. Such varied lesions are encountered more often in pediatric than in adult $\mathrm{CM}$ where a more uniform presentation of small patches and papules is common [1-5].

The bullous form of mastocytosis is a rare, morbid condition typically encountered in young children [2]. Episodic blistering has been reported in maculopapular $\mathrm{CM}$, which usually occurs after stroking or rubbing of the lesional skin and rarely appears spontaneously [4]. There are also reports of nodular forms with occasional blistering as well as predominant bullous variants of CM. In fact, the long-living bullous manifestations are characteristic of the diffuse CM [3-5]. It is interesting that in our case, the varied skin lesions, not corresponding to diffuse $\mathrm{CM}$, were associated with an uninterrupted bulla formation for half a year and no improvement with $\mathrm{H} 1$ receptor blockers or topical corticosteroids/antibiotics.

In our case, the flushing episodes were very frequent, spontaneous, and not induced by any precipitating factor (ambient temperature, food, exercise, stress, medication, etc.). This was the only systemic clinical symptom. No other signs of internal organ involvement were revealed except for an STL of $11.8 \mathrm{ng} / \mathrm{ml}$. This is not indicative of systemic mastocytosis, where the STL reference value is $>20 \mathrm{ng} / \mathrm{ml}$. This slightly elevated STL might relate to flushing as a single symptom of the mast cell mediator release. It is observed more often in patients with systemic involvement, but may also occur in those with purely cutaneous manifestations [1-6].

In our case, the diagnosis of $\mathrm{CM}$ was made based on clinical manifestations, Darier's sign, and histopathological and immunohistochemical findings (anti-c-kit/CD117 with a high specificity and sensitivity for mast cells). It is widely accepted that growth and differentiation and proliferation of mast cells are controlled by the tyrosine kinase receptor c-Kit (CD117) and its ligand stem cell factor. It is also controlled by other cytokines such as IL-4, IL-6, IL-10, and IL-13 $[1,2]$. Recent genetic studies have identified new proteins (Lin28b) that are of interest in mast cell disease [7].

Adequate management during the early phase of $\mathrm{CM}$ in children may prevent potential complications. Counseling of patients/parents is important to avoid mediator release precipitating factors and treat mast cell mediator release symptoms. CM remissions have been reported following treatments with anti-mediator drugs such as $\mathrm{H} 1$ and $\mathrm{H} 2$ receptor antagonists and cromolyn sodium (oral and topical). Topical/intralesional corticosteroids, phototherapy, and topical calcineurin inhibitors may be useful [8-10]. 
In our case, considering the previous therapy failure, we applied a short course of methylprednisolone, combined with an $\mathrm{H} 1$ receptor blocker (levocetirizine) and topical mid-potency corticosteroid. This was followed by intermittent $\mathrm{H} 1$ receptor blocker (ketotifen) and topical hydrocortisone courses. This treatment reduced the patient's persistent blistering and the frequency of flushing episodes. No adverse events occurred. The 3-year-long follow-up demonstrated that our approach to a refractory, though not severe, clinical form of $\mathrm{CM}$ can be to the patient's benefit. Of note, neither low-dose $\mathrm{H} 2$ receptor blockers (for pediatric use) nor sodium cromoglycate are available in Bulgaria.

The debate between more or less aggressive management options for pediatric CM continues. Systemic and topical corticosteroids have demonstrated good therapeutic results in some cases of bullous mastocytosis, as reported in the literature $[11,12]$.

\section{CONCLUSION}

Childhood CM usually has a benign course and most of the cases resolve by puberty $[2,3]$. With proper treatment and family education on avoiding triggering factors, gradual resolution of both skin lesions and mast cell-mediated symptoms may be observed. Despite the lack of systemic involvement, some patients with $\mathrm{CM}$ may develop skin manifestations that are difficult to control. Therefore, follow-up with rigorous evaluation and relevant management is required for each individual case.

\section{ACKNOWLEDGMENTS}

No funding or sponsorship was received for this study or the publication of this article. All named authors meet the International Committee of Medical Journal Editors (ICMJE) criteria for authorship for this manuscript, take responsibility for the integrity of the work as a whole, and have given final approval for the version to be published.

Conflict of interest. R. Yankova, T. Abadjieva, and V. Belovezhdov declare that they have no conflict of interest.

Compliance with ethics guidelines. All procedures followed were in accordance with the ethical standards of the responsible committee on human experimentation (institutional and national) and with the Helsinki Declaration of 1964, as revised in 2013. Informed consent was obtained from the patient's parents for the child being included in the study and for the publication of the patient photographs.

Open Access. This article is distributed under the terms of the Creative Commons Attribution Noncommercial License which permits any noncommercial use, distribution, and reproduction in any medium, provided the original author(s) and the source are credited.

\section{REFERENCES}

1. Valent P, Akin C, Escribano L, et al. Standards and standardization in mastocytosis: consensus statements on diagnostics, treatment recommendations and response criteria. Eur J Clin Invest. 2007;37:435-53.

2. Carter MC, Metcalfe DD, Komarow HD. Mastocytosis. Immunol Allergy Clin $\mathrm{N}$ Am. 2014;34:181-96.

3. Castells M, Metcalfe DD, Escribano L. Diagnosis and Treatment of Cutaneous Mastocytosis in Children. Practical Recommendations. Am J Clin Dermatol. 2011;12:259-70. 
4. Lange M, Niedoszytko M, Renke J, Glen J, Nedoszytko B. Clinical aspects of paediatric mastocytosis: a review of 101 cases. J Eur Acad Dermatol Venereol. 2013;27:97-102.

5. Lee HJ, Jang MJ, Bae EY, et al. Bullous cutaneous mastocytosis, a rarely reported disease in Asian children. Asian Pac J Allergy Immunol. 2014;32:354-7.

6. Valent P, Sperr WR, Sotlar K, et al. The serum tryptase test: an emerging robust biomarker in clinical hematology. Expert Rev Hematol. 2014;7:683-90.

7. Wang LD, Rao TN, Rowe RG, et al. The role of Lin28b in myeloid and mast cell differentiation and mast cell malignancy. Leukemia. 2015. doi:10. 1038/leu.2015.19 [Epub ahead of print].

8. Arock M, Akin C, Hermine O, Valent P. Current treatment options in patients with mastocytosis: status in 2015 and perspectives. Eur J Haematol. 2015. doi:10.1111/ejh.12544 [Epub ahead of print].

9. Cardet JC, Akin C, Lee MJ. Mastocytosis: update on pharmacotherapy and future directions. Expert Opin Pharmacother. 2013;14:2033-45.

10. Edwards AM, Capková S. Oral and topical sodium cromoglicate in the treatment of diffuse cutaneous mastocytosis in an infant. BMJ Case Rep. 2011;29:2011.

11. Verma KK, Bhat R, Singh MK. Bullous mastocytosis treated with oral betamethasone therapy. Indian J Pediatr. 2004;71:261-3.

12. Has C, Misery L, David L, Cambazard F. Recurring staphylococcal scalded skin syndrome-like bullous mastocytosis: the utility of cytodiagnosis and the rapid regression with steroid. Pediatr Dermatol. 2002;19:220-3. 